\title{
Inhaled Nitric Oxide Prevents Experimental Platelet Activating Factor-Induced Shock
}

\author{
Sherif Emil, MD, CM; Joel Berkeland, RRT; Mahmoud Kosi, MD; James Atkinson, MD
}

Objective: To investigate whether inhaled nitric oxide (INO) can prevent platelet activating factor (PAF)induced pulmonary hypertension and shock.

Design: Randomized controlled animal trial.

Sehing: Laboratory.

Subjects: Yorkshire swine.

Intervemtions: Animals received general anesthesia and invasive hemodynamic monitoring, then PAF only, 2.5 $\mu \mathrm{g} / \mathrm{kg}$ intravenously over 45 minutes (PAF group, $\mathrm{n}=9$ ) or PAF in addition to INO, $20 \mathrm{ppm}$ (PAF-INO group, $n=6)$.

Main Oulcomes: Vascular pressures (mean arterial and mean pulmonary), vascular resistance indexes (systemic and pulmonary), cardiac indexes, and oxygen delivery and oxygen consumption.

Results: Mean arterial pressures, cardiac indexes, and oxygen delivery and consumption were significantly higher in the PAF-INO group. Mean pulmonary arterial pressures and systemic and pulmonary vascular resistance indexes were significantly lower in the PAF-INO group. There were 4 deaths $(44 \%)$ in the PAF group vs none $(0 \%)$ in the PAF-INO group $(P=.10)$.

Conclusion: The use of INO prevents pulmonary hypertension, circulatory failure, and death during PAFinduced shock.

Arch Surg. 1996;131:855-860
From the Division of Pediatric Surgery, Childrens Hospital, Los Angeles, Calif.

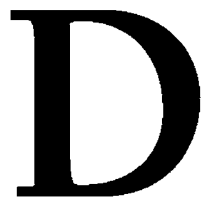

ESPITE MAJOR advances in critical care and antimicrobial therapy, septic shock remains an entity with high morbidity and mortality rates. In humans, septic shock is characterized by an early hyperdynamic phase, in which cardiac output is elevated and systemic vascular resistance (SVR) is depressed. During refractory sepsis, a hypodynamic phase ensues and is characterized by systemic hypotension, pulmonary hypertension, depressed cardiac function, and progressive multiplesystem organ failure. Patients who reach this terminal phase of septic shock commonly succumb to their illness.

Platelet activating factor (PAF) has been shown to be a critical mediator in septic shock and multiple-system organ failure. ${ }^{1-3}$ In swine, PAF infusion results in hypodynamic shock with significant pulmonary hypertension. ${ }^{4}$ This model reproduces the right ventricular dysfunction seen in human sepsis. ${ }^{5-10}$ If the pulmonary hypertension component contributes significantly to this form of shock, resolution of the pulmonary hypertension should lead to improved hemodynamic status and perfusion. In this study, a group of swine in PAF-induced shock were treated with the selective pulmonary vasodilator and inhaled nitric oxide (INO) and compared with an untreated group in similar shock.

\section{RESUITS}

Four animals died in the PAF group (44\% mortality) vs none in the PAF-INO group $(P=.10)$. Three of the four animals died within 15 minutes of beginning the PAF infusion with an acute cor pulmonale and cardiogenic shock picture (low MAP, low cardiac index, high CVP, and high PVRI). The fourth animal died after progressive decline in MAP and cardiac index and persistent elevation in PVRI 90 minutes af-

\section{See Materials and Methods on next page}




\section{MATERIALS AND METHODS}

\section{ANIMAL PREPARATION}

Fifteen adolescent Yorkshire swine weighing 17 to $22 \mathrm{~kg}$ were used. The animals were first examined by a veterinarian and housed for 2 days prior to experimentation to exclude underlying illness or infection. On the day of experimentation, the animals were first sedated with intramuscular atropine $(0.04 \mathrm{mg} / \mathrm{kg})$, xylazine $(3.5 \mathrm{mg} / \mathrm{kg})$, and ketamine $(12.5 \mathrm{mg} /$ $\mathrm{kg}$ ) prior to halothane induction and endotracheal intubation. A 12F temperature probe (Hewlett-Packard 21090A, Hewlett-Packard, Andover, Mass) was inserted in the rectum, a veterinary pulse oximeter probe (Nellcor Inc, Hayward, Calif) was placed on the tongue or snout, and electrocardiogram limb leads were affixed. Under continuous halothane anesthesia $(0.8 \%-1 \%)$, a cutdown on the right external jugular vein allowed placement of a double-lumen $7 \mathrm{~F}$ central venous catheter (Cook Inc, Bloomington, Ind) in the superior vena cava. A continuous infusion of normal saline ( $4 \mathrm{~mL} / \mathrm{kg}$ per hour) was then started and continued for the duration of the experiment. A femoral cutdown was then performed. A femoral artery catheter was placed for continuous systemic blood pressure monitoring and arterial blood gas analyses. A 6F or 7F pulmonary artery catheter (American Edwards Laboratories, Irvine, Calif) was introduced through the femoral vein. Through a $4-\mathrm{cm}$ vertical paramedian left lower-quadrant incision, the urinary bladder was identified and catheterized with a Foley catheter secured with a purse string suture. This completed the surgical procedure.

The animal was then transferred to volume-controlled ventilation (Servo 900C, Siemens-Elema, Solna,
Sweden) and ventilation parameters set as follows: fractional inspired oxygen, ie, $\mathrm{FiO}_{2}, 0.25$; respiratory rate, 12; tidal volume, 10 to $12 \mathrm{~mL} / \mathrm{kg}$ to maintain $\mathrm{PaCO}_{2}$ at 35 to 45 $\mathrm{mm} \mathrm{Hg}$. Continuous balanced anesthesia was maintained with halothane $(0.8 \%-1 \%)$ and pancuronium $(0.2 \mathrm{mg} / \mathrm{kg}$ per hour $)$. Animals were allowed a 1-hour stabilization period before being randomized to the protocol described below. At the termination of the experiment, animals that survived were killed with intravenous injection of pentobarbital sodium (120 $\mathrm{mg} / \mathrm{kg}$ ). The protocol was approved by the Childrens Hospital, Los Angeles, Animal Care Committee and adhered to the National Institutes of Health guidelines on the care and handling of experimental animals.

\section{EXPERIMENTAL PROTOCOL}

After baseline hemodynamic parameters were recorded $\left(\mathrm{T}_{0}\right)$, animals were randomized to 1 of 2 groups. The first group (PAF group, $n=9$ ) received a PAF bolus ( $L-\alpha-$ phosphatidylcholine- $\beta$-acetycholine- $\gamma$ - $O$-alkyl in chloroform solution [Sigma Chemical, St Louis, Mo]) at a dose of $2.5 \mu \mathrm{g} / \mathrm{kg}$ over 45 minutes. The second group received the same dose of $\mathrm{PAF}$ in addition to inhaled nitric oxide (INO) (Gilmore Liquid Air, San Gabriel, Calif) at a dose of $20 \mathrm{ppm}$, starting simultaneously with the PAF infusion and continuing for 2 hours (PAF-INO group, $n=6$ ). Animals were followed up for 3 hours after the PAF infusion started. The solution was stored at $-10^{\circ} \mathrm{C}$. Prior to each experiment, $500 \mu \mathrm{g}$ of PAF was mixed with $25 \mathrm{~mL}$ of normal saline to produce PAF at a $20-\mu \mathrm{g} / \mathrm{mL}$ solution and allowed to reach room temperature. This solution was then administered as a bolus at a rate of $2.5 \mu \mathrm{g} / \mathrm{kg}$ per hour for 30 minutes, followed by ter the start of the PAF infusion. The potency of the PAF infusion and the early high mortality rate necessitated starting the INO simultaneously with the PAF infusion in the PAF-INO group.

Data for all continuous variables are reported as mean \pm SEM. Table 1 shows the hemodynamic parameters of the 2 groups at baseline $\left(\mathrm{T}_{0}\right)$ and at each subsequent experimental hour $\left(T_{1}, T_{2}\right.$, and $\left.T_{3}\right)$. In all animals, PAF was given as a bolus over 45 minutes starting at $T_{0}$. In group 2, INO was started at $\mathrm{T}_{0}$ and discontinued immediately after $T_{2}$ values were recorded. There were no significant differences in CVP or PCWP at any time point between the 2 groups.

Toble 2 shows the oxygenation and perfusion values of the 2 groups at the same time points. There was no significant difference in weight between the 2 groups (PAF group, $18.84 \pm .82 \mathrm{~kg}$; PAF -INO group, 19.33 \pm .70 $\mathrm{kg} ; \mathrm{P}=.66$ ). In this model, $\mathrm{PAF}$ infusion did not result in significant leukocytosis, hemoconcentration, acidosis, or hyperglycemia. There were no significant differences between the 2 groups with respect to the initial or final white blood cell count, hemoglobin concentration, hematocrit index, or platelet count. There were also no significant differences between the 2 groups with respect to the final levels of total $\mathrm{CO}_{2}$, glucose, blood urea nitrogen, or creatinine. Inhaled NO therapy did not result in significant methemoglobinemia (PAF group, $1.24 \% \pm 0.04 \%$ of total hemoglobin; PAF-INO group, $1.17 \% \pm 0.15 \%$ of total hemoglobin; $P=.66$ ). During INO therapy, $\mathrm{NO}_{2}$ levels did not rise over 1 ppm.

\section{COMMHNT}

The last decade has witnessed a flurry of research into the mechanisms of septic shock and potential therapies. Most recently, the roles of PAF and NO have attracted significant attention because of the possibility of immediate therapeutic interventions based on blocking the action or production of these 2 substances.

Platelet activating factor is a biologically active phospholipid found as an inactive precursor in the plasma membranes of immune and endothelial cells. ${ }^{2,3}$ Ample investigative evidence has implicated PAF as a critical, and perhaps the most potent, mediator of septic shock. ${ }^{1-3,11-17}$ Acute circulatory collapse, characterized by increased oxygen extraction, metabolic acidosis, and death, was seen in dogs after PAF infusion. ${ }^{12}$ In the same animal, Yamanaka et $\mathrm{al}^{13}$ showed a biphasic hypotensive response to PAF. The first phase was characterized by decreased SVR and increased cardiac output, while the second phase showed the reverse hemodynamic profile, in addition to increased PVR. This is very similar to the biphasic hemodynamic profile seen in human sepsis. Immune and endothelial cells stimulated by tumor necro- 
$5.0 \mu \mathrm{g} / \mathrm{kg}$ per hour for 15 minutes. This total dose and rate of infusion were found to approximate the median lethal dose $\left(\mathrm{LD}_{50}\right)$ for PAF during pilot experiments to establish our model.

\section{MONITORING}

The weight of each animal (in kilograms) was recorded just prior to experimentation. During the course of the experiment, electrocardiogram, heart rate, mean arterial pressure (MAP), mean pulmonary arterial pressure (MPAP), central venous pressure (CVP), and temperature were continuously monitored by a temperature and pressure bedside monitor (Hewlett-Packard 78534C) and recorded at baseline and every 30 minutes. Pulmonary capillary wedge pressure (PCWP) and thermodilution cardiac output were measured and recorded at baseline and every 30 minutes by computer (9520A Cardiac Output Computer, American Edwards Laboratories). Systemic (SVR) and pulmonary vascular resistance (PVR) indexes (SVRI and PVRI, respectively) were calculated by the following formulas:

$$
\begin{aligned}
& \text { SVRI }=[\text { (MAP-CVP) } \times 80 / \\
& \text { (Cardiac Output) }] / \text { Weight }
\end{aligned}
$$

and

$$
\begin{aligned}
& \text { PVRI }=[(\text { MPAP }- \text { PCWP }) \times 80 / \\
& \text { (Cardiac Output })] / \text { Weight } .
\end{aligned}
$$

Hemoglobin saturation with oxygen was continuously monitored by pulse oximeter (model N-100, Nellcor Inc) and recorded at baseline and every 30 minutes. Arterial and mixed venous blood gases were measured at baseline and every hour with a blood analyzer (model 170 pH/Blood Gas Analyzer, Corning, Mayfield, Mass). Oxygen delivery, oxygen consumption, and extraction ratio were calculated by standard formulas at baseline and every hour. Hourly urine output was recorded at baseline and for the duration of the experiment. During INO therapy, NO and nitric dioxide $\left(\mathrm{NO}_{2}\right)$ were continuously monitored on line by an electrochemical analyzer (Pulmonox II, Pulmonox, Tofield, Alberta).

A complete blood cell count was obtained at baseline and at the end of each experiment; $\mathrm{Na}^{+}, \mathrm{K}^{+}, \mathrm{Cl}^{-}$, total $\mathrm{CO}_{2}$, glucose, blood urea nitrogen, creatinine, and methemoglobin levels were obtained at the end of each experiment.

\section{STATISTICAL ANALYSIS}

The differences in continuous outcome variables were compared between the PAF and PAF-INO groups at baseline and at each subsequent hour, using a combination of the $\mathrm{F}$ test and Student $t$ test. The F test was used for any significant difference in the variance of the outcome variable between the 2 groups. A Student $t$ test, assuming either equal or unequal variance, was then used to test the difference in the outcome variable itself between the 2 groups. Data from animals that did not survive the experiment were excluded from the above analysis. The Fisher exact test was used to test the difference in the mortality rates between the groups. A $P$ value of $\leq .05$ was considered statistically significant. All analyses were performed using Microsoft Excel 3.0 Analysis Tools (Microsoft Inc, Hayward) and were reviewed by an independent statistician. sis factor release PAF, which in turn amplifies the cytokine response. ${ }^{14}$ Antagonists of PAF have been shown to prevent hemodynamic collapse in sepsis models and to attenuate cytokine induction during endotoxemia. ${ }^{15-17}$ These observations all point to PAF as a major player in septic shock and the systemic inflammatory response syndrome. Models of PAF-induced sepsis, therefore, have important clinical implications.

Research into the role of NO in the hemodynamic changes accompanying sepsis has produced somewhat inconclusive results. Several animal models of sepsis have pointed to increased production of NO by the inducible NO synthase (NOS) enzyme as an etiologic factor responsible for the systemic vasodilation during the hyperdynamic phase. ${ }^{11,18}$ The implication of this finding is that NOS inhibition may present a novel approach to treat the hemodynamic derangements in septic shock. Clinical experience has so far been scarce, but anecdotal reports of the hemodynamic benefits of NOS inhibitors have appeared. ${ }^{19,20}$ Recently, Gomez-Jimenez et al ${ }^{21}$ demonstrated increased plasma nitrite and nitrate (the stable end products of endogenous NO synthesis) concentrations in patients with septic shock and correlated those levels directly with endotoxin concentration and cardiac output and inversely with systolic blood pressure. ${ }^{21}$ Furthermore, investigations in rats and dogs have raised the possi- bility that PAF-induced hypotension may, in fact, be mediated by enhanced NO production. . $^{22-24}$

However, results of animal trials have tempered the enthusiasm for using NOS inhibitors to treat septic shock by demonstrating detrimental effects of NOS inhibition during sepsis on the hemodynamic, as well as the immune, levels. ${ }^{25-27}$ An explanation for these detrimental hemodynamic effects is the propensity of NOS inhibitors to worsen pulmonary hypertension, leading to rightsided heart failure and decreased cardiac output. ${ }^{26,27}$ In support of this explanation, a hemodynamic benefit to NOS inhibitors during sepsis was realized when these compounds were combined with INO to decrease PVR or with dobutamine to augment cardiac performance. ${ }^{27.28}$ Furthermore, endothelium-dependent vasorelaxation (ie, NO production) may actually be decreased in the hypodynamic stage of sepsis. ${ }^{29}$

The critical role of right ventricular dysfunction during human sepsis has been reported by several investigators. ${ }^{5-10}$ Hoffman et $\mathrm{al}^{5}$ and Reuse et $\mathrm{al}^{7}$ demonstrated significant right ventricular dysfunction during sepsis and showed improvement in right ventricular function to be a predictive factor for clinical improvement and survival. Dhainaut et $\mathrm{al}^{8}$ and Parker et $\mathrm{al}^{9}$ demonstrated significant and universal right ventricular dysfunction in septic patients. Redl et $\mathrm{al}^{10}$ showed that patients with right ventricular dysfunction did not respond to fluid resus- 


\begin{tabular}{|c|c|c|c|c|}
\hline \multirow{2}{*}{$\begin{array}{l}\text { Hemodynamic Parameter } \\
\text { Experimental Groupt }\end{array}$} & \multicolumn{4}{|c|}{ Time Polnts, h } \\
\hline & $T_{0}$ & $T_{1}$ & $T_{2}$ & $\mathbf{T}_{\mathbf{8}}$ \\
\hline \multicolumn{5}{|l|}{$\mathrm{cl}, \mathrm{ml} \cdot \mathrm{min}^{-1} \mathrm{~kg}^{-1}$} \\
\hline PAF & $81.6 \pm 4.7$ & $35.4 \pm 8.4$ & $60.9 \pm 7.1$ & $63.6 \pm 8.2$ \\
\hline \multirow{2}{*}{\multicolumn{5}{|c|}{ MAP, $\mathrm{mm} \mathrm{Hg}$}} \\
\hline & & & & \\
\hline PAF & $67 \pm 4$ & $39 \pm 6$ & $47 \pm 4$ & $47 \pm 4$ \\
\hline PAF-INO & $58 \pm 2$ & $57 \pm 21$ & $53 \pm 1$ & $54 \pm 2$ \\
\hline \multicolumn{5}{|l|}{ SVRI, dyne $\cdot \mathrm{sec} \cdot \mathrm{cm}^{-5} \cdot \mathrm{kg}^{-1}$} \\
\hline PAF & $172 \pm 17$ & $239 \pm 34$ & $158 \pm 21$ & $150 \pm 21$ \\
\hline PAF-INO & $136 \pm 13$ & $159 \pm 16 \neq$ & $115 \pm 10$ & $120 \pm 10$ \\
\hline \multicolumn{5}{|l|}{ MPAP, $\mathrm{mm} \mathrm{Hg}$} \\
\hline PAF & $15.0 \pm 0.4$ & $29.0 \pm 1.1$ & $26.0 \pm 3.4$ & $18.0 \pm 2.1$ \\
\hline PAF-INO & $17.0 \pm 0.7$ & $22,0 \pm 1,37$ & $15.0 \pm 0.87$ & $18.0 \pm 0.6$ \\
\hline \multicolumn{5}{|l|}{ PVRI, dyne $\cdot \mathrm{sec} \cdot \mathrm{cm}^{-5} \cdot \mathrm{kg}^{-1}$} \\
\hline PAF & $17.0 \pm 2.2$ & $158.0 \pm 39.6$ & $66.0 \pm 18.1$ & $33.0 \pm 9.4$ \\
\hline PAF-INO & $16,0 \pm 1.2$ & $39.0 \pm 5.0 \neq$ & $16.0 \div 2.3 t$ & $23.0 \pm 3.0$ \\
\hline \multicolumn{5}{|l|}{ HR, beats/min } \\
\hline PAF-INO & $\begin{array}{l}74 \pm 2 \\
91 \pm 7\end{array}$ & $\begin{array}{r}116 \pm 20 \\
114 \pm 17\end{array}$ & $\begin{array}{l}104 \div 13 \\
107 \pm 14\end{array}$ & $\begin{array}{c}93 \pm 8 \\
105 \pm 13\end{array}$ \\
\hline
\end{tabular}

${ }^{*} \mathrm{Cl}$ indicates cardiac index; PAF, platelet activating factor; INO, inhaled nitric oxide; MAP, mean arterial pressure; SVRI, systemic vascular resistance index; MPAP, mean pulmonary arterial pressure; PVRI, pulmonary vascular resistance index; and HR, heart rate. Values are mean $\pm S E M$.

†PAF group ( $n=9)$ includes only animals that survived ( $n=5)$; PAF-INO group ( $n=6)$.

$\ddagger \mathrm{P}<.05$ compared with PAF group.

\section{Table 2. Oxygenation and Perfusion Outcomes*}

\begin{tabular}{|c|c|c|c|c|}
\hline \multirow{2}{*}{$\begin{array}{l}\text { Oxygenation and Perfusion Parameterf } \\
\text { Experimental Groupt }\end{array}$} & \multicolumn{4}{|c|}{ Time Polnts, h } \\
\hline & $T_{0}$ & $T_{1}$ & $T_{2}$ & $T_{3}$ \\
\hline \multicolumn{5}{|l|}{$\mathrm{PaO}_{2}, \mathrm{~mm} \mathrm{Hg}$} \\
\hline PAF & $107 \pm 8$ & $79 \pm 11$ & $94 \pm 7$ & $102 \div 7$ \\
\hline PAF-INO & $113 \pm 3$ & $113 \pm 6 \neq$ & $108 \pm 5$ & $106 \pm 10$ \\
\hline \multicolumn{5}{|l|}{$\mathrm{DO}_{2}, \mathrm{~mL} \mathrm{O}_{2} \cdot \mathrm{min}^{-1}$} \\
\hline $\begin{array}{l}\text { PAF } \\
\text { PAF-INO }\end{array}$ & $\begin{array}{l}209 \pm 11 \\
208 \pm 18\end{array}$ & $\begin{array}{r}85 \pm 18 \\
170 \pm 18 \neq\end{array}$ & $\begin{array}{l}156 \pm 14 \\
212 \pm 15 t\end{array}$ & $\begin{array}{l}163 \pm 15 \\
212 \pm 18\end{array}$ \\
\hline \multicolumn{5}{|l|}{$\mathrm{VO}_{2}, \mathrm{~mL} \mathrm{O}_{2} \cdot \mathrm{min}^{-1}$} \\
\hline PAF & $80 \pm 16$ & $46 \pm 7$ & $64 \pm 9$ & $63 \pm 7$ \\
\hline PAF-INO & $77 \pm 6$ & $72 \pm 5 \ddagger$ & $71 \pm 5$ & $79 \pm 5$ \\
\hline \multicolumn{5}{|l|}{ Extraction ratio, \% } \\
\hline $\begin{array}{l}\text { PAF } \\
\text { PAF-INO }\end{array}$ & $\begin{array}{l}40 \pm 7 \\
38 \pm 5\end{array}$ & $62 \pm 11$ & $\begin{array}{l}42 \pm 5 \\
34 \pm 3\end{array}$ & $\begin{array}{l}40 \pm 6 \\
39 \pm 5\end{array}$ \\
\hline \multicolumn{5}{|l|}{ Urine output, $\mathrm{mL} \cdot \mathrm{kg}^{-1} \mathrm{~h}^{-1}$} \\
\hline $\begin{array}{l}\text { PAF } \\
\text { PAF-INO }\end{array}$ & $\begin{array}{l}1.72 \pm 0.18 \\
1.47 \pm 0.11\end{array}$ & $\begin{array}{l}1.01 \div 0.33 \\
0.96 \pm 0.14\end{array}$ & $\begin{array}{l}0.45 \pm 0.25 \\
0.75 \pm 0.19\end{array}$ & $\begin{array}{l}0.55 \pm 0.28 \\
1.04 \pm 0.24\end{array}$ \\
\hline
\end{tabular}

*PAF indicates platelet activating factor; INO, inhaled nitric oxygen; $\mathrm{DO}_{2}$, oxygen delivery; and $\mathrm{VO}_{2}$, oxygen consumption. Values are mean $\pm S E M$. †PAF group ( $n=9)$ includes only animals that survived ( $n=5)$; PAF-INO group ( $n=6)$.

$\ddagger \mathrm{P}<.05$ compared with PAF group.

citation and required catecholamine therapy. Right ventricular dysfunction during sepsis has various causes, pulmonary hypertension being a leading one. ${ }^{6} \mathrm{~A}$ right ventricle that is unable to pump blood against an increased afterload dilates acutely and fails. This acute cor pulmonale picture quickly leads to left ventricular failure by severely reducing left ventricular preload and restricting left ventricular pumping action through intrapericardial pressure effects. Pulmonary hypertension may also increase ventilation-perfusion mismatch and the shunt fraction, leading to hypoxia.

Our septic model using PAF infusion was characterized by systemic hypotension, pulmonary hyperten- sion, decreased cardiac output, increased SVR, decreased oxygen delivery and consumption, and high mortality. These are all stigmata of the late or hypodynamic phase of human septic shock, making this model very relevant to that clinical situation. Therapeutic intervention with selective pulmonary vasodilation using INO dramatically reduced PVR, in turn resulting in an improved systemic hemodynamic profile and perfusion.

The improvement in cardiac index lasted beyond the INO treatment period. Death resulting from acute, fulminant cor pulmonale was also prevented by INO. In our model, severe right ventricular dysfunction, rather than 
enhanced NO production, appears to be the critical cause of shock and death secondary to PAF infusion. This finding, in combination with the previous studies mentioned above, would indicate that the hypotensive mechanisms of PAF may be species dependent. We have previously ${ }^{30}$ shown that swine in severe cardiogenic shock secondary to acute hypoxic cor pulmonale can be resuscitated with INO as a sole agent. Recent studies ${ }^{31,32}$ showing therapeutic hemodynamic benefits of INO in other gram-positive and gram-negative septic shock models are also in concert with the results reported here.

Therefore, measures to prevent hyperproduction of NO may be of benefit during early or hyperdynamic sepsis, as long as the systemic vasopressor effect is not offset by significant pulmonary vasoconstriction. In late or hypodynamic sepsis, diagnosing and treating pulmonary hypertension and right ventricular dysfunction may be the key to improving hemodynamic profile, oxygenation, and prognosis.

The clinical correlate of the findings reported here is obvious. Patients suffering from hypodynamic septic shock with significant pulmonary hypertension may benefit from INO. Randomized controlled human trials will be needed to define this patient population and elucidate any possible therapeutic benefits.

Presented at the 67th Annual Session of the Pacific Coast Surgical Association, San Diego, Calif, February 18, 1996.

Statistical assistance was provided by Linda S. Chan, PhD, Research and Biostatistics Division, Departments of Pediatrics and Emergency Medicine, Los Angeles CountyUniversity of Southern California Medical Center.

Correspondence: James Atkinson, MD, Division of Pediatric Surgery, University of California at Los Angeles Medical Center, 10833 LeConte Ave, Box 951749, Los Angeles, CA 90025-1749.

\section{REFERENCES}

1. Andersen BO, Bensard DD, Harken AH. The role of platelet activating factor and its antagonists in shock, sepsis, and multiple organ failure. Surg Gynecol Obstet. 1991;172:415-424.

2. Lefer AM. Induction of tissue injury and altered cardiovascular performance by platelet-activating factor: relevance to multiple system organ failure. Crit Care Clin. 1989;5:331-351.

3. Koltai M, Hosford D, Braquet PG. Platelet-activating factor in septic shock. New Horiz. 1993;1:87-95.

4. Goldstein RE, Ezra D, Laurindo FRM, Feuerstein GZ. Coronary and pulmonary vascular effects of leukotrienes and PAF-acether. Pharmacol Res Comm. 1986; 18(suppl):151-162.

5. Hoffman MJ, Greenfield LJ, Sugerman HJ, Tatum JL. Unsuspected right ventricular dysfunction in shock and sepsis. Ann Surg. 1983;198:307-319.

6. Sibbald WJ, Driedger AA. Right ventricular function in acute disease states: pathophysiologic considerations. Crit Care Med. 1983;11:339-345.

7. Reuse C, Frank N, Contempre B, Vincent $J$ L. Right ventricular function in septic shock. Intensive Care Med. 1988;14:486-487.

8. Dhainaut JF, Lanore JJ, de Gournay JM, et al. Right ventricular dysfunction in patients with septic shock. Intensive Care Med. 1988;14:488-491.

9. Parker MM, McCarthy KE, Ognibene FP, Parrillo JE. Right ventricular dysfunction and dilatation, similar to left ventricular changes, characterize the cardiac depression of septic shock in humans. Chest. 1990;97:126-131.

10. Redl G, Germann P, Plattner H, Hammerle A. Right ventricular function in early septic shock states. Intensive Care Med. 1993;19:3-7.

11. Szabo C. Alterations in nitric oxide production in various forms of circulatory shock. New Horiz. 1995;3:2-32.

12. Bessin $P$, Bonnet J, Apffel D, et al. Acute circulatory collapse caused by platelet- activating factor (PAF-acether) in dogs. Eur J Pharmacol. 1983;86:403-413.

13. Yamanaka S, Miura K, Yukimura T, Okumura M, Yamamoto K. Putative mechanism of hypotensive action of platelet-activating factor in dogs. Circ Res. 1992; 70:893-901

14. Camussi G, Bussolino F, Salvidio G, Baglioni C. Tumor necrosis factor/ cachectin stimulates peritoneal macrophages, polymorphonuclear neutrophils, and vascular endothelial celis to synthesized and release plateletactivating factor. $J$ Exp Med. 1987;166:1390-1404.

15. Handley DA, Tomesch JC, Saunders RN. Inhibition of PAF-induced systemic responses in the rat, guinea pig, dog, and primate by the receptor antagonist SRI 63-441. Thromb Haemost. 1986;56:40-44.

16. Stanton AWB, Izumi T, Antoniw JW, Piper PJ. Platelet-activating factor (Paf) antagonist, WEB 2086, protects against Paf-induced hypotension in Macaca fascicularis. Br J Pharmacol. 1989;97:643-646.

17. Kuipers $B$, van der Poll $T$, Levi $M$, ef al. Platelet-activating factor antagonist TCV-309 attenuates the induction of the cytokine network in experimental endotoxemia in chimpanzees. J Immunot. 1994;152:2438-2446.

18. Booke $M$, Meyer J, Lingnau $W$, Hinder $F$, Traber LD, Traber DL. Use of nitric oxide synthase inhibitors in animal models of sepsis. New Horiz. 1995;3:123138.

19. Nava E, Palmer RMJ, Moncada S. Inhibition of nitric oxide synthesis in septic shock: how much is beneficial? Lancet. 1991;338:1555-1557.

20. Petros A, Bennett $D$, Vallance $P$. Effects of nitric oxide synthase inhibitors on hypotension in patients with septic shock. Lancet. 1991;338:1557-1558.

21. Gomez-Jimenez J, Salgado A, Mourelle M, et al. L-Arginine: nitric oxide pathway in endotoxemia and human septic shock. Crit Care Med. 1995;23:253258.

22. Takekoshi K, Kasai $\mathrm{K}$, Suzuki $\mathrm{Y}$, et al. Effect of $\mathrm{N}^{6}$-nitro-L-arginine on shock induced by endotoxin and by platelet activating factor in dogs. Eur $J$ Pharmacol. 1993;250:465-467.

23. Szabo C, Wu CC, Mitchell JA, et al. Platelet-activating factor contributes to the induction of nitric oxide synthase by bacterial lipopolysaccharide. Circ Res. 1993;73:991-999.

24. Moritoki H, Hisayama $T$, Takeuchi S, Miyano $H$, Kondoh $W$. Involvement of nitric oxide pathway in the PAF-induced relaxation of rat thoracic aorta. $\mathrm{Br} J$ Pharmacol. 1992;107:196-201.

25. Minnard EA, Shou J, Naama H, Cech A, Gallagher H, Daly JM. Inhibition of nitric oxide synthesis is detrimental during endotoxemia. Arch Surg. 1994; 129:142-148.

26. Robertson FM, Offner PJ, Ciceri DP, Becker WK, Pruitt BA. Detrimental hemodynamic effects of nitric oxide synthase inhibition in septic shock. Arch Surg. 1994;129:149-156.

27. Ogura $H$, Offiner $P J$, Saiton $D$, et al. The pulmonary effect of nitric oxide synthase inhibition following endotoxemia in a swine model. Arch Surg. 1994; 129:1233-1239.

28. Kilbourn RG, Cromeens DM, Chelly FD, Griffith OW. NG-methyl-L-arginine, an inhibitor of nitric oxide formation, acts synergistically with dobutamine to improve cardiovascular performance in endotoxemic dogs. Crit Care Med. 1994; 22:1835-1840.

29. Wang $P, B a Z F$, Chaudry IH. Nitric oxide: to block or enhance its production during sepsis? Arch Surg. 1994;129:1137-1143.

30. Emil S, Kosi M, Berkeland J, Kanno S, Newth C, Atkinson J. Severity of hypoxia predicts response to nitric oxide in a porcine pulmonary hypertension model. J Pediatr Surg. 1995;30:930-936.

31. Berger JI, Gibson RL, Redding GJ, Standaert TA, Clarke WR, Truog WE. Effect of inhaled nitric oxide during group B streptococcal sepsis in piglets. Am Rev Respir Dis. 1993;147:1080-1086.

32. Offner PJ, Ogura $H$, Jordan BS, Pruitt BA, Cioffi WG. Effects of inhaled nitric oxide on right ventricular function in endotoxin shock. J Trauma. 1995;39: 179-186.

\section{DISCUSSION}

Robert S. Sawin, MD, Seattle, Wash: This group has used the model of septic shock, which represents a very severe challenge to these animals with a $44 \%$ mortality rate, apparently due to acute cor pulmonale, a nearly $50 \%$ reduction in cardiac index, a 100\% increase in pulmonary artery pressure, and a 10 fold increase in pulmonary vascular resistance. These deleterious effects were nearly eliminated with the use of inhaled nitric oxide, and all of the animals treated with nitric oxide survived. You mentioned the biphasic nature of the septic shock, the first phase, warm or hyperdynamic shock, and the second phase, cold, hypodynamic shock. It would appear that the model 
you used with the PAF infusion is replicating only the physiology of the hypodynamic shock. What is known about endogenous PAF levels in serum or pulmonary vasculature during sepsis, that is, is the PAF activity a biphasic response or is the response to an increased PAF level a biphasic reaction? As an extension of that, why didn't the animals in your study demonstrate a hyperdynamic phase prior to the profound hypodynamic shock?

Your results suggest that the mortality associated with the PAF-induced shock is predominantly related to pulmonary hypertension, which can be completely overcome by inhaled nitric oxide. You mentioned in the manuscript paper that there is a lot of conflicting data in the literature regarding the role of $\mathrm{NO}$ in the hyperdynamic phase of shock. If NO is going to be used clinically for the treatment of septic shock, will the timing of NO inhalation be crucial, that is, if we use it early in the hyperdynamic phase of shock, would it be detrimental, or would you predict that it will prevent the progression to hypodynamic physiology?

Over the past several years many of us in pediatrics have been excited about the use of NO for treating pulmonary hypertension, especially in neonates. But our experience at Children's Hospital in Seattle with this treatment has been somewhat sobering. Over the first several hours, many of the children have an excellent response to nitric oxide, but eventually they seem to develop a tachyphylaxis requiring higher doses and eventually they become unresponsive to that treatment. Have you repeated these sorts of studies in these animals for a longer time to see if the therapeutic response to NO can be maintained? This paper suggests that nitric oxide may well become a portion of our armamentarium against sepsis, and I look forward to hearing about more work from your group.

Kenneth Waxman, MD, Orange, Calif: To suggest a clinical trial is quite premature because the actions of nitric oxide and of PAF are much more complicated than just pulmonary vasoconstriction and vasodilatation. Both have many other effects. For example, both nitric oxide and PAF effect WBC activation. The effects of inhaled nitric oxide on leukocyte activation are not well understood; the effects of this in sepsis are even less predictable.

H. Atik, MD, Idyllwild, Calif: My understanding of the beneficial effects of nitric oxide is 2-fold. One is vasodilatation, as the author described, through the endothelial system and relaxation of smooth muscle. The other one is the inhibition of platelet release and platelet aggregation. I wonder if the authors would make any comments whether or not they have studied platelet function and whether there is any justification for trying other antiplatelet agents in their model.

James W. Holcroft, MD, Sacramento, Calif: Inhaled nitric oxide blocks hypoxic pulmonary vasoconstriction. On the one hand that could well be good, as the authors pointed out, because it would lessen the hindrance that the pulmonary vasculature imposes on the right ventricle and thereby allow the cardiovascular system to respond favorably to the septic insult. But, on the other hand, hypoxic pulmonary vasoconstriction has been with us for many millions of years as a key defensive process in any ill patient in responding to collapse or flooding of alveoli. Have the authors measured shunt fractions or alveolar arterial $\mathrm{O}_{2}$ gradients or $\mathrm{PaO}_{2} / \mathrm{FiO}_{2}$ indices to see if they changed in response to the NO administration?

John K. MacFarlane, MD, Vancouver, British Columbia: Perhaps I missed it, but when exactly was the nitric oxide delivered? Was it delivered at the same time as the insult or shortly thereafter? If you have information on when it be- comes effective or perhaps when it is ineffective could you share it with us?

Dr Atkinson: Dr Sawin, you asked about the clinical measurement of platelet activating factor in these patients who are undergoing late phases of sepsis, and I think it is a biphasic response. There is an early peak of PAF in patients who are septic, which then rapidly declines with the metabolism of the product, and then there is a sustained elevation that persists through the later phases of shock. That is important in this model. In this model, we are using pharmacological doses of platelet activating factor and not levels that you would commonly see in vivo.

As far as the use and timing of the nitric oxide administration in the hyperdynamic early phases of shock vs the later hypodynamic phases, it is unlikely that nitric oxide-induced pulmonary vasodilatation would be effective in the hyperdynamic phase in preventing progression. It is of interest though that it may be useful to use nitric oxide in combination with very powerful vasopressors such as a $\mathrm{N}$-AME $\mathrm{CN}$-arginine methyl chloride, which is a product that is a nitric oxide in hibitor which can't be used because it causes such hypoxia from pulmonary vasoconstriction, but if you combine that with inhaled nitric oxide, it might be a very powerful agent to use early in the vasodilatory phases of shock.

I share your experience with newborn application of nitric oxide. It has not been as useful as we had hoped that it would be for patients who have just pulmonary hypertension and not necessarily the same as in this discussion with sepsis and all of the other factors that are going on at that time.

Dr Waxman pointed out that a clinical trial may be premature. That is very true. Many of the agents that we test as new agents for treatment of complex diseases suffer from this same problem: that there are many factors that may be going on that we do not understand. There may be many effects of the drug that we are going to trial that may not be apparent at the time that we initiate that trial. But there is on the horizon a time when we might want to apply nitric oxide to the treatment of sepsis, particularly in patients in whom we can demonstrate a proven pulmonary hypertension and right heart failure component.

Dr Atik has been one of my mentors and has long guided me in thinking about platelets and platelet aggregation. In this particular study, we did measure the platelet counts and those did not decline. We did not have any formal platelet aggregation studies or any other more sophisticated measures of plate let activity.

Dr Holcroft I think correctly pointed out that there may be adverse effects of nitric oxide blocking the alveolar hypoxic response in the lungs, and that those may have a detrimental effect on the patients' ability to oxygenate. That is a valid consideration. We did not measure any changes in the VQ fractions in these animals. It would be something that might be useful to look at in the future, particularly if we were using a lung injury type of model of sepsis.

Dr MacFarlane asked an important question about the timing of the nitric oxide delivery. The nitric oxide was started at the same time as the platelet activating factor was infused. This was necessitated by the severity of this insult and the fact that the pigs would probably not survive to receive the nitric oxide if we didn't initiate it at the time of the infusion.

That leaves open a clinical question about what are the consequences of this study as far as being able to use nitric oxide therapeutically. Will it work when it is somewhat after the fact, after the patient produces the PAF as a cytokine that produces these syndromes? That question would need to be addressed in subsequent studies. 